\title{
TAHAPAN BERPIKIR MAHASISWA DALAM MENGONSTRUKSI BUKTI MATEMATIS
}

\author{
Syukma Netti \\ Universitas Bung Hatta \\ syukmaneti@bunghatta.ac.id
}

\begin{abstract}
Abstrak
Mengonstruksi bukti matematis merupkan bentuk khusus dari pemecahan masalah sehingga perlu proses berpikir yang sedikit berbeda. Penelitian ini bertujuan untuk merumuskan tahapan berpikir mahasiswa dalam menelesaikan masalah pembuktian. Metoda penelitian yang digunakan adalah metoda kualitatif. Pengumpulan data dilakukan dengan memberikan satu masalah pembuktian kepada 10 orang mahasiswa. Mahasiswa diminta melakukan think aloud ketika sedang berupaya mengonstruksi bukti. Semua aktifitas di rekap dengan camera video. Hasil kerja yang dianalisis adalah yang hasil konstruksi bukti yang valid. Temuan dari penelitian ini adalah ada 5 tahapan berpikir mahasiswa ketika berupaya menghasilkan konstruksi bukti yang valid, yaitu (1) memahami masalah pembuktian, (2) membuat koneksi dan menyeleksi, (3) Menemukan ide utama,(4) merangkai bukti dan menimpulkan, dan (5) melakukan refleksi.
\end{abstract}

Kata kunci: konstruksi bukti, proses berpikir, fungsi komposisi.

\begin{abstract}
Constructing mathematical proofs is a special case of problem solving so it needs a slightly different thinking process. This study aims to formulate the stages of student thinking in solving the problem of proof. The research method used is qualitative method. Data collection was done by giving two models of proof problem to 17 students. Students were asked to think aloud while trying to construct of proof. All activities were recaps with video camera. The results of the analyzed work were those of valid proof construction. The findings of this study were five stages of student thinking when attempt to construct a valid construction proof, namely (1) understanding the problem of proof, (2) making connections and selecting, (3) finding the main idea, (4) assembling evidence and concluding, and (5) doing reflection.
\end{abstract}

Keywords: Constructing proof, thinking process, composition function

Sitasi: Netti, S. 2018. Tahapan Berpikir Mahasiswa dalam Mengonstruksi Bukti Matematis. Matematika dan Pembelajaran, 6(1), 1-10. 


\section{PENDAHULUAN}

Kemampuan mengonstruksi bukti matematis merupakan keahlian yang penting yang harus dimiliki oleh matematikawan dan mahasiswa matematika (Dreyfus, 2017; Susanna, 1994; Weber, 2001). Susanna (1994) menyatakan bahwa kemampuan mengonstruksi bukti merupakan kemampuan yang harus dimiliki oleh matematikawan. Weber (2001) menjelaskan bahwa kemampuan mengonstruksi bukti merupakan keterampilan penting bagi semua matematikawan. Alcock \& Weber (2001) menyatakan bahwa tujuan utama pembelajaran matematika lanjut adalah meningkatkan kemampuan mahasiswa untuk mengonstruksi bukti formal..

Penelitian terkait kajian konstruksi bukti telah dilakukan oleh beberapa ahli (Arbib, 1990; Selden \& Selden, 1996, 2003, 2008, 2014; Weber, 2001, 2006; Torregrosa \&Quesada, 2008; Stylianides \& Stylianides, 2009; Tabach, M. dkk, 2009). Arbib (1990) membahas tentang pendekatan artifisial intelegensi untuk mengonstruksi bukti. Selden \& Selden $(1987,2003,2008,2014)$ membahas tentang konstruksi bukti dan mendesain model pembelajaran yang efektif dalam pembelajaran bukti. Stylianides \& Stylianides (2009) dan Tabach, M. dkk (2009) membahas kemampuan konstruksi bukti pada guru dan calon guru.

Konstruksi bukti dipandang sebagai bentuk khusus dari pemecahan masalah. Weber (2005) menyatakan bahwa aktifitas yang berkenaan dengan pembuktian dapat dipandang sebagai pemecahan masalah dengan tingkat kompleksitas yang lebih tinggi karena harus meyakinkan orang lain dan diri sendiri. Furinghetti, F., \& Morselli, F. (2009). menyatakan bahwa bukti merupakan kasus khusus dari pemecahan masalah. Mengingat kekhususan dari konstruksi bukti matematis yaitu meyakinkan seseorang secara logis tentang kebenaran sebuah pernyataan matematis, maka tahapan kostruksi bukti matematis membutuhkan tahapan berpikir tersendiri. Tahapan berpikir dalam pemecahan masalah dirasa kurang sesuai untuk memecahkan masalah pembuktian.

Penelitian lain yang juga membahas tahapan dalam mengonstruksi bukti matematis adalah Bekalties dkk (2016) dan Weber (2004). Kedua peneliti sama-sama mengaji prosedur mengonstruksi bukti dalam pembelajaran bukti. Bekelties menyebutnya kerangka kerja bukti sedangkan weber 2004 menyebutnya prosedur untuk mengonstruksi bukti. Penelitian ini lebih fokus pada proses berpikir mahasisiwa dalam mengonstruksi bukti. Sehingga tujuan penelitian ini adalah mendeskripsikan tahapanproses berpikir mahasiswa dalam mengonstruksi bukti matematis.

\section{METODE}

Penelitian ini mendeskripsikan proses berpikir mahasiswa ketika berupaya mengonstruksi bukti matematis. Oleh karena itu, metoda penelitian yang digunakan adalah metoda penelitiian kualitatif (Creswell, 2012). Subjek penelitian ini adalah 10 orang mahasiswa jurusan matematika di Universitas Negeri Malang yang telah lulus matakuliah analisis riil dan kalkulus. Mereka diberi satu masalah pembuktian yang harus mereka selesaikan. Selama mengerjakan masalah pembuktian, mereka diminta untuk menyuarakan apa yang mereka pikiran (think aloud). Peneliti mengamati dan merekam prilaku subjek secara audiovisual dengan menggunakan kamera video. Selanjutnya, dilakukan 
wawancara untuk memperjelas proses berpikir mereka.

Berikut ini adalah masalah pembuktian yang diberikan kepada subjek:

Misalkan $A, B$, dan $C$ adalah subset dalam bilangan real. Dan $f: A \rightarrow B$ dan $g: B \rightarrow C$

adalah fungsi injeksi, maka buktikan bahwa $g$ o $f$ adalah fungsi bijective juga.

Fokus penelitian adalah menganalisis tahap yang dilakukan oleh subjek (siswa), sehingga hasil konstruksi bukti yang dianalisis adalah hasil konstruksi bukti yang valid. Dalam penelitian ini, didapat dua hasil kerja mahasiswa yang valid. Maka proses berpikir dalam mengonstruksi bukti yang di paparkan dalam artikel ini adalah hasil pengamatan terhadap dua orang mahasiswa.

\section{HASIL DAN PEMBAHASAN}

Penelitian ini bertujuan untuk merumuskan tahapan berpikir mahasiswa dalam mengonstruksi bukti matematis. Untuk mendapatkan data, diminta mahasiswa melakukan menyelesaikan dua masalah pembuktian dengan cara think aloud. Berdasarkan data dari hasil kerja mahasiswa, diidentifikasi aktifitas fisik dan mental yang dilakukan mahasiswa untuk mengetahui tahap berpikirnya. Tabel berikut merupakan hasil pengamatan prilaku mahasiswa dalam mengonstruksi bukti matematis

Tabel 1. Hasil pengamatan dan wawancara terhadap Subjek I

\begin{tabular}{|c|c|}
\hline \multicolumn{2}{|c|}{ Subjek I } \\
\hline Hasil Pengamatan & Hasil Konstruksi Bukti \\
\hline $\begin{array}{l}\text { Membaca masalah pembuktian } \\
\text { secara keseluruhan. } \\
\text { Let } \mathrm{A}, \mathrm{B} \text { and } \mathrm{C} \text { are subset in real } \\
\text { number. } f: A \rightarrow B \text { and } f: B \rightarrow C \text {. If } \\
f \text { and } g \text { are injective function, then } \\
\text { prove that } g \circ f \text { is bijective function } \\
\text { too. } \\
\text { S1 langsung dapat menentukan apa } \\
\text { yang harus dibuktikan. } \\
\text { Namun, untuk menyelesaikan S1 } \\
\text { perlu membaca satu persatu bagian } \\
\text { dari soal secara pelan-pelan sambil } \\
\text { menuliskan bagian yang dianggap } \\
\text { penting menyelesaikan soal } \\
\text { pembuktian ini.. } \\
f: A \rightarrow B f \text { is injective function } \\
f: B \rightarrow C g \text { is injective function }\end{array}$ & $\begin{array}{l}\text { g०f : } A \rightarrow C \\
\text { diketahui : } \\
f: A \rightarrow B \text { merupatan fungsi injektir } \\
g: B \rightarrow C \text { merupakan fungsi injektif }\end{array}$ \\
\hline
\end{tabular}


Netti, S. 2018. Tahapan Berpikir Mahasiswa... Matematika dan Pembelajaran, 6(1), 4 of 10

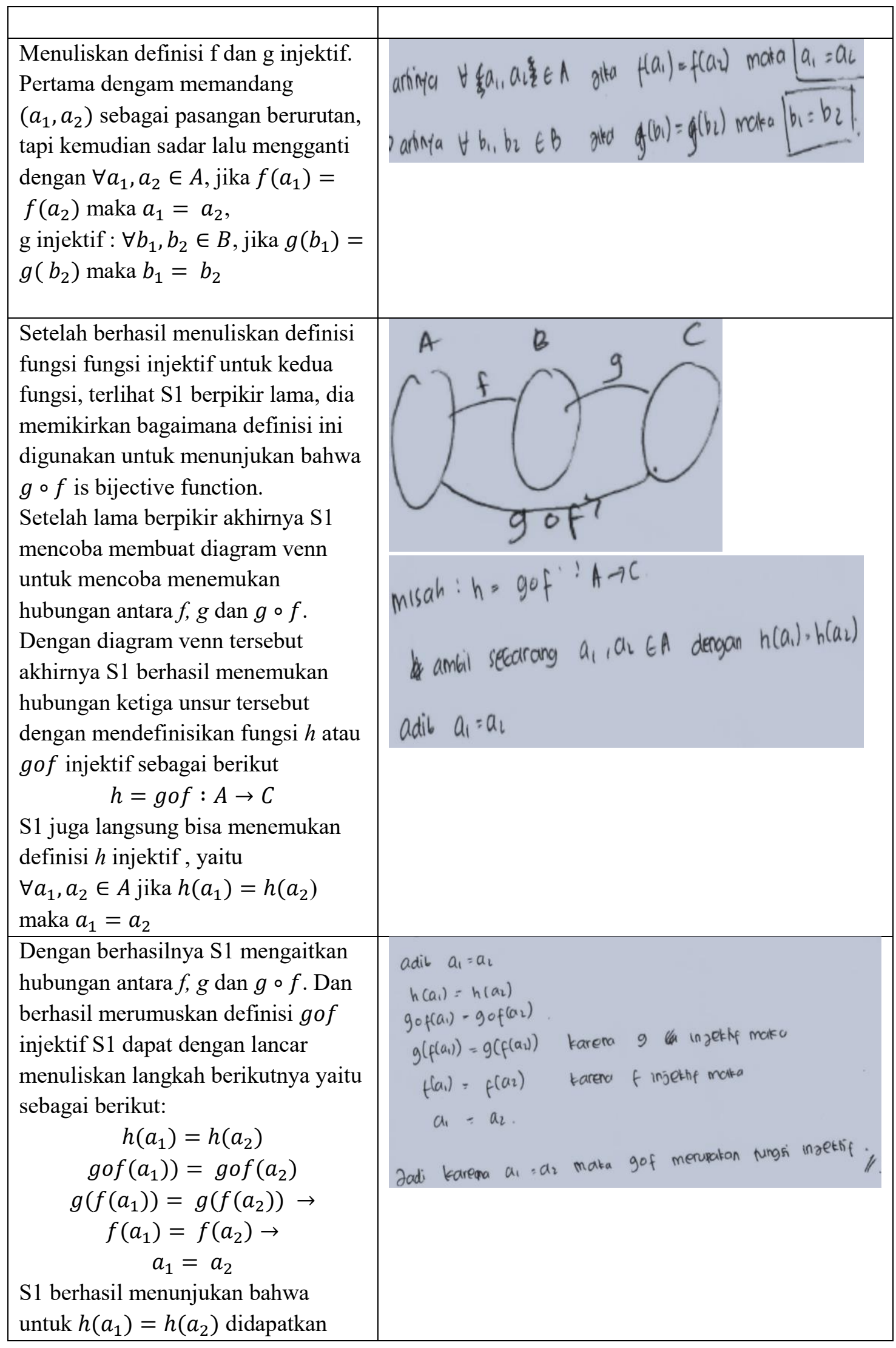


$a_{1}=a_{2}$, sehingga dengan yakin $\mathrm{S} 1$ menyimpulkan bahwa benar terbukti bahwa gof adalah fungsi injektif.

Setelah selesai menuliskan kesimpulan dengan memberi tanda terbukti pada bagian akhir, terlihat S1 membaca ulang soal dan semua hasil kerjanya, sebelum dia melihat ke peneliti dan mengatakan udah buk, udah terbukti.

Hasil kerja dan proses berpikir S2 hampir sama dengan proses berpikir S1 dengan sedikit perbedaan dalam penulisan. Berikut hasil pengamatan dan wawancara terhadap S2

Tabel 2. Hasil pengamatan dan wawancara terhadap Subjek II.

\begin{tabular}{|c|c|}
\hline Subjek II & \\
\hline Hasil Pengamatan & Hasil Konstruksi Bukti \\
\hline $\begin{array}{l}\text { Membaca dan memahami } \\
\text { masalah pembbuktian dan } \\
\text { menuliskan yang } \\
\text { diketahui. } \\
\text { g of } \text { satu-satu }\end{array}$ & $\begin{array}{ll}\text { Diketahin } & f: A \rightarrow B \quad f, g \text { satu-satu } \\
& g: B \rightarrow C \quad \text { Det } A R b: \quad g \text { of satu-satu }\end{array}$ \\
\hline $\begin{array}{l}\text { S2 mencoba memikirkan } \\
\text { definisi dan teorema yang } \\
\text { terkait dengan masalah } \\
\text { pembuktian. } \\
\text { S2 lalu menuliskan } \\
\text { definisi f dan g injektif. } \\
\text { Pertama dengam Cuma } \\
\text { mengambil satu } x \in A, \\
\text { tapi kemudian sadar lalu } \\
\text { mengganti dengan } \\
\forall x_{1}, x_{2} \in A, \text { jika } f\left(x_{1}\right)= \\
f\left(x_{2}\right) \text { maka } x_{1}=x_{2}, \\
\text { g injektif : } \forall x_{1}, x_{2} \in B, \\
\text { jika } g\left(x_{1}\right)=g\left(x_{2}\right) \text { maka } \\
x_{1}=x_{2}\end{array}$ & $\begin{array}{l}\text { Xf satu satu berarti } \\
\forall x_{1} \in A \quad f\left(u_{1}\right)=f\left(u_{2}\right) \text { maka } x_{1}=x_{2} \\
f\left(u_{1}\right), f\left(u_{2}\right) \in B \\
\text { xg savesatu } \\
\forall u_{1}, u_{2} \in B . \quad g\left(u_{1}\right)=f\left(u_{2}\right) \text { maka } x_{1}=x_{2}\end{array}$ \\
\hline
\end{tabular}




\begin{tabular}{|c|c|}
\hline $\begin{array}{l}\text { Dengan waktu yang tidak } \\
\text { terlalu lama, sekitar } 5 \\
\text { menit, S2 dapat } \\
\text { menemukan cara } \\
\text { bagaimana pernyataan } \\
\text { yang diberikan harus } \\
\text { dibuktikan. S2 sempat } \\
\text { salah dalam membuat } \\
\text { keputusan tetapi cepat } \\
\text { sadar. } \\
\text { Awalnya menetapkan } \\
g^{\circ} f ; B \rightarrow \\
C \text { dan } f\left(x_{1}\right), f\left(x_{2}\right) \in B \\
\text { Cepat disadari bahwag } o \\
f: A \rightarrow C \text {, sehingga } \\
\text { berhasil memetapkang } o \\
f \text { injektif berarti } \forall x_{1}, x_{2} \in \\
A \rightarrow \\
(g o f)\left(x_{1}\right)=(g o f)\left(x_{2}\right) \\
\text { Adit } x_{1}=x_{2}\end{array}$ & $\begin{array}{l}g \circ f(x)=g(f(u)) \\
\text { Aubut sebaray } f\left(x_{c}\right),\left(x_{2}\right) \in B \\
(g \circ f(u) \text { satu satu } \\
\forall x_{1}, x_{2} \in A \quad(g \circ f)\left(u_{1}\right)=(g \circ f)\left(x_{2}\right) \\
\text { Adt: } x_{1}=x_{2}\end{array}$ \\
\hline 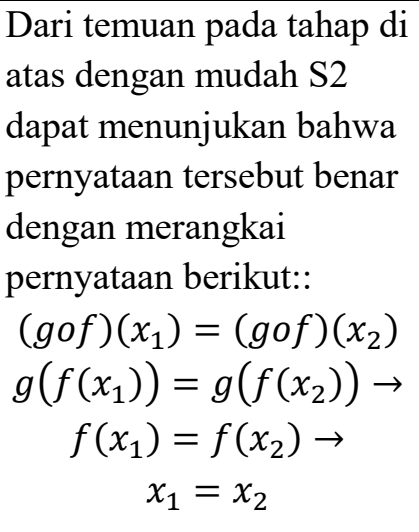 & $\begin{array}{l}(g \circ f)\left(u_{1}\right)=20 \\
(g \circ f)\left(x_{2}\right)=g\left(f\left(x_{2}\right)\right) \\
f\left(x_{1}\right)=f\left(x_{2}\right) \\
\text { * Karena } g \text { nya satu-satu \& } f\left(x_{1}\right), f\left(x_{2}\right) \in B \\
\text { maka } f\left(x_{1}\right)=f\left(u_{2}\right) . \\
f\left(u_{1}\right)=f\left(x_{2}\right) . \\
\text { Farena f nya satu satu maka } x_{1}=x_{2} . \\
d a d \text { terbulet }\end{array}$ \\
\hline$\therefore$ gof injektif. & \\
\hline $\begin{array}{l}\text { Sekilas, S2 membaca } \\
\text { ulang dan mencek lagi } \\
\text { apa yang telah ditulis } \\
\text { lalu memutuskan, ya } \\
\text { yakin... } \\
\text { Dengan ucapan sudah } \\
\text { terbukti buk. }\end{array}$ & \\
\hline
\end{tabular}

Data dalam tabel di atas merupakan gabungan 3 data tentang proses konstruksi bukti mahasiswa dalam menghasilka konstruksi bukti yang valid yaitu data pengamatan, data wawancara dan data hasil kerja mahasiswa. Ketiga cara pengambilan data tersebut sangat 
cukup untuk menggambarkan proses berpikir mahasiswa. Selama pengamatan, peneliti sudah membuat dugaan bahwa proses berpikirnya ada 5 tahap sesuai dengan jumlah baris dalam tabel di atas. 5 tahap tersebut tidak ditemukan kesesuaian dengan tahapan pemecahan masalah dari Polya (1955) dan tiga fase penanganan pertanyaan dengan teliti (tackling question conscientiously) dari Mason, Burton \& Stacey dkk (2010). Empat prinsip pemecahan masalah dari Polya adalah (1) memahami masalah, (2) menemukan rencana pemecahan, (3) menjalankan pemecahan, dan (4) melihat kembali. Sedangkan tiga fase penanganan masalah Mason, Burton \& Stacey (2010) yang merupakan pengembangan dari prinsip pemecahan masalah dari Polya, yaitu entry, attack dan review. Penanganan masalah dari Mason, Burton \& Stacy (2010) merupakan perluasan dari prinsip pemecahan dari Polya, yang menekankan pada saat menghadapai kebuntuan.

Dengan melakukan perbandingan data temuan pada kedua tabel di atas dengan prinsip pemecahan masalah dari Polya (1955) dan tiga fase penanganan pertanyaan dengan teliti dari Mason, Burton \& Stacey dkk (2010), peneliti merumuskan tahapan proses berpiikir mahasiswa dalam menghasilkan konstruksi bukti yang valid. Ditemukan 5 tahapan berpikir mahasiswa ketika sedang berupaya menghasilkan konstruksi bukti yang valid. Kelima tahapan berpikir dapat dijelaskan sebagai berikut.

1. Memahami masalah pembuktian

Pada tahap ini, awalnya mahasiswa membaca masalah pembuktian secara sekilas untuk mendapatkan maksud dari masalah yang diberikan secara keseluruhan. Kemudian, mereka membaca lagi untuk fokus pada makna dari masing-masing bagian bagian yang diketahui, seperti maksud dari injektif. Pada kebanyakan mahasiswa yang tidak berhasil mengonstruksi bukti yang valid diawali dengan tidak mengerti beberapa istilah yang ada pada masalah pembuktian. Setelah mendapatkan maknanya baru mereka menulisakan unsur-unsur yang diketahui seperti yang terlihat pada hasil kerja subjek pada baris pertama pada tabel 1 dan tabel 2. Kedua subjek menghabis waktu yang hampir sama dalam menjalankan tahap ini.

2. Membuat Koneksi dan menyeleksi

Setelah kedua subjek berhasil memahami setiap unsur dalam masalah pembuktian, mereka mencoba mencari konsep dan prinsip yang berkaitan dengan unsur-unsur yang diketahui, seperti definisi dari fungsi bijektif. Hal ini harus dilakukan agar dapat dibangun hubungan antara unsur-unsur yang diketahui dengan konklusi yang akan dibuktikan. Jadi, dalam hal ini yang harus diuraikan bukan saja unsur-unsur yang diketahui tetapi juga konklusi dari penyataan pada masalah pembuktian. Mahasiswa harus dapat menguraikan keduanya dengan baik. Tahap ini sedikit berbeda dengan tahap membuat rencana penyelesaian dari prinsip pemecahan masalah dari Polya karena penekanan pada masalah pembuktian. Tahap ini lebih menekankan pada mengurai premis dan konklusi untuk melihat relasinya dan untuk tujuan membangun rangkaian pembuktian.

3. Menemukan ide Utama

Menemukan ide utama maksudnya adalah menemukan satu konsep yang dapat mengaitkan antara unsur-unsur yang ada pada premis dengan konklusi. Dalam penelitian ini kedua subjek memliki ide yang berbeda dalam mengaitkan antara premis-premis dan konklusi. Kedua subjek juga menghabiskan waktu yang cukup jauh 
berbeda dalam menemukan ide utamanya. S2 lebih cepat dalam menemukan ide utama dan idenya juga cukup sederhana. S1 membutuhkan waktu hampir setengah jam bahkan membutuhkan gambar diagram venn untuk dapat melihat hubungan premis dan konklusi secara nyata. Bagian ini merupakan bagian yang sangat penting dalam tahap mengonstruksi bukti karena tahap ini sangat menentukan apakah pembuktian bisa berhasil atau tidak. Dalam penelitian ini, tahap ini juga merupakan tahap yang sangat menarik karena pada tahap ini kedua subjek memiliki cara yang berbeda dan sama-sama benar.

\begin{tabular}{|c|c|}
\hline Ide utama dari S1 & Ide utama dari S2 \\
\hline $\begin{array}{l}\text { misah: } h=g \text { of : } A \rightarrow C \\
\text { ambil secarang } a_{1}, a_{2} \in A \text { dengan } h\left(a_{1}\right) \cdot h(c) \\
\text { adil } a_{1}=a_{2}\end{array}$ & $\begin{array}{l}(g \circ f(u) \text { satv -satu } \\
\forall x_{1}, x_{2} \in A_{A} \quad(g \circ f)\left(u_{1}\right)=(g \circ f) f \\
\text { Adt : } x_{1}=x_{2}\end{array}$ \\
\hline
\end{tabular}

4. Merangkai Bukti dan menyimpulkan

Membuktian sebuah pernyataan memiliki berbagai cara, salah satu dengan cara pembuktian langsung. Pembuktian langsung adalah dengan cara mengaikan secara langsung antara premis (p) dengan konklusi (q). Secara simbol penulisan rangkaian pembuktian langsung dapat dinyatakan seperti rangkaian berikut $p \Rightarrow p_{1} \Rightarrow p_{2} \Rightarrow$ $\cdots \Rightarrow p_{n} \Rightarrow q$. Dimana $p_{i} \Rightarrow p_{j}$ adalah definisi atau teorema-teorema yang saling terkait. Maka pada tahap ini mahasiswa harus memiliki pengetahuan yang baik tentang defini dan teorema yang dibutuhkan untuk dirangkai agar dapat dihasilkan bukti yang valid. Dari tabel 1 dan tabel 2 di atas dapat dilihat bahwa rangkaian bukti kedua subjek memuat definisi fungsi komposisi dan definisi fungsi injektif. Mereka tidak menggunakan simbol yang sama. Jadi dalam tahap ini, mahasiswa juga harus mampu membuat koneksi antara satu konsep dengan konsep lain atau antara satu teorema dengan teorema lainnya.

\section{Merefleksi}

Mencek dan meninjau ulang keseluruhan pekerjaan, mulai dari membaca ulang masalah pembuktian hingga hasil hasil konstruksi yang telah dikerjakan dengan tujuan untuk memastikan bahwa kesimpulan yang dibuat memang benar-benar telah sesuai.

Hasil penelitian yang hampir mendekati sama dengan temuan ini adalah hasil penelitian Weber (2004). Namun, dalam penelitiannya Weber (2004) tidak dalam kontek proses berpikir tapi sebagai prosedur dalam mengonstruksi bukti matematis. Perbedaan yang lain adalah Weber tidak menguraikan secara rinci tahapan dalam mengaplikasikan teorema dan konsep yang telah dimiliki.

\section{KESIMPULAN DAN SARAN}

Perbedaan yang signifikan antara proses berpikir dalam menyelesaikan masalah dengan proses berpikir dalam mengonstruksi bukti adalah pada bagaimana proses berpikir pada setiap tahap yang orientasinya adalah membangun rangkaian langkah-langkah untuk 
menunjukan suatu pernyataan benar. Sedangkan, pada pemecahan masalah biasa adalah lebih fokus pada menemukan cara untuk mendapatkan apa yang diinginkan soal. Hal tersebut mengakibatkan tahapan proses berpikirnya jadi lebih banyak yaitu 5 tahapan proses berpikir. 5 tahapan proses berpikir dalam mengonstruksi bukti itu adalah (1) memahami masalah pembuktian, (2) membuat koneksi dan menyeleksi, (3) Menemukan ide utama,(4) merangkai bukti dan menimpulkan, dan (5) melakukan refleksi.

Berdasaran kesimpulan dapat disarankan pada dosen atau guru yang mengajarkan materi tentang pembuktian agar mengenalkan 5 tahapan proses berpikir dalam mengonstruksi bukti matematis. Dalam mengajarkan juga dibiasakan untuk digunakan sehingga mahasiswa memiliki pemahaman dan arahan yang baik dalam mempelajari dan mengerjakan masalah pembuktian.

\section{DAFTAR RUJUKAN}

Arbib, A.M. (1990). A Piagetian Perspective on Mathematical Construction. Synthesis, Volume 84, Issue 1, pp 43-58 doi:10.1007/BF00485006.

Benkhalti, A \& Selden, A, \& Selden, J (2016). Proof Frameworks--A Way to Get Started, (online) https://www.researchgate.net/publication/299532808 diakses April 2016 DOI: 10.13140/RG.2.1.4160.9368

Creswell, J.W. (2012). Educational Research: Planning, Conducting and Evaluating Quantitative and Qualitatitive Research, Fourth edition , Boston, Amsterdam, Delhi. Pearson.

Dreyfus, T \& Gabel, M. (2017). Affecting the Flow of a Proof by Creating PresenceCase Study in Number theory. Educational Studies Mathematics. Vol 96 Issue 2 pp 187-205. Spinger

Furinghetti, F., \& Morselli, F. (2009). Every unsuccessful problem solver is unsuccessful in his or her own way: Affective and cognitive factors in proving. Educational Studies of Mathematics, 70, 71-90.

Mason, J., Burton, L.,Stacey, K. (2010). Thinking Mathematically. Edisi kedua. Prentice Hall. Harlow

Netti, S. Nusantara, T., Subanji, Abadyo \& Anwar, L. (2016). The Failure to Construct Proof Based on Assimilation and Accommodation Framework from Piaget. International Education Studies; Vol. 9, No. 12; 2016

Polya, G. (1973). How To Solve It. Edisi kedua. Cetakan kedua. Princeton University Press ISBN 0-691-08097-6.

Selden, A \& Selden, J. (1996). The Role Of Logic In The Validation Of Mathematical Proofs.presented at the DIMACS Symposium on Teaching 
Logic and Reasoning, Rutgers University,25 - 26 July 1996.

Selden, A. \& Selden, J. (2003). Validations of proofs written as texts: Can undergraduates tell whether an argument proves a theorem? Journal for Researchin Mathematics Education, 34, 4-36.

Selden, A. \& Selden, J. (2008). Overcoming students' difficulties in learning to understand and construct proofs. In M. Carlson \& C. Rasmussen (Eds.), Making the connection: Research and teaching in undergraduate mathematics (pp.95-110). Washington, DC: Mathematical Association of America.

Selden, J., Benkhalti, A \& Annie Selden. (2014). An Analysis Of Transition-ToProof Course Students' Proof Constructions With A View Towards Course Redesign(online) : https://www.researchgate.net/publication/268278836. Diakses Desember 2016.

Selden, A. (2004). How Students Learn to Construct and Understand Proofs Presented in AAAS Symposium The Changing Nature of Proof in Mathematics: Past, Present, Future, February di New Mexico State University.

Selden, A. \& Selden, J. (2015). A Theoretical Perspective for Proof Construction. CERME 9 Proceeding. (didownload melalui www.researchgate.net tanggal 12 Pebruari 2016.

Tabach, M \& Levenson, E \& Barkai, R \& Tsamir, P. Tirosh, D \& Dreyfus, T .(2009). Teachers' Knowledge of Students' Correct and IncorrectProof Constructions in Fou-Lai Lin, Feng-Jui Hsieh Gila Hanna, Michael de Villiers (Eds) Proceeding ICMI 19th The Department of Mathematics, National Taiwan Normal University Taipei, Taiwan.

Weber, K. (2001). Student difficulty in constructing proofs: the need for strategic knowledge. Educational Studies in Mathematics, 48, 101-119.

Weber, K. (2004). A Framework for Describing the Processes that Undergraduates Use to Construct Proofs. Proccedings of the 28th Confrence of the International Group for the Psychology of Mathematics Education. Vol 4. pp. 425-432.

Weber, K. (2006) . Investigating and teaching the processes used to construct proofs. In F. Hitt, G. Harel \& S. Hauk (Eds.), Research in Collegiate Mathematics Education. VI (pp.197-232). Providence: RI: American Mathematical Society. DOI: 10.1090/cbmath/013/07. 